\title{
Identification of bistable populations of Porphyromonas gingivalis that differ in epithelial cell invasion
}

Correspondence

G. P. Stafford

G.stafford@sheffield.ac.uk

C. W. I. Douglas

I.Douglas@sheffield.ac.uk

Received 19 January 2010

Revised 28 May 2010

Accepted 21 June 2010

\author{
S. Suwannakul, G. P. Stafford, S. A. Whawell and C. W. I. Douglas \\ Oral and Maxillofacial Pathology, School of Clinical Dentistry, The University of Sheffield, \\ Sheffield S10 2TA, UK
}

\begin{abstract}
Bistable populations of bacteria give rise to two or more subtypes that exhibit different phenotypes. We have explored whether the periodontal pathogen Porphyromonas gingivalis exhibits bistable invasive phenotypes. Using a modified cell invasion assay, we show for the first time that there are two distinct subtypes within a population of $P$. gingivalis strains NCTC 11834 and W50 that display differences in their ability to invade oral epithelial cells. The highly invasive subtype invades cells at 10-30-fold higher levels than the poorly invasive subtype and remains highly invasive for approximately 12-16 generations. Analysis of the gingipain activity of these subtypes revealed that the highly invasive type had reduced cell-associated arginine-specific protease activity. The role of Arg-gingipain activity in invasion was verified by enhancement of invasion by $\operatorname{rgp} A B$ mutations and by inclusion of an Arg-gingipain inhibitor in invasion assays using wild-type bacteria. In addition, a population of $\triangle \operatorname{rgp} A B$ bacteria did not contain a hyperinvasive subtype. Screening of the protease activity of wild-type populations of both strains identified high and low protease subtypes which also showed a corresponding reduction or enhancement, respectively, of invasive capabilities. Microarray analysis of these bistable populations revealed a putative signature set of genes that includes oxidative stress resistance and iron transport genes, and which might be critical to invasion of or survival within epithelial cells.
\end{abstract}

\section{INTRODUCTION}

The ability of micro-organisms to survive within changing environments is dependent upon their ability to withstand stresses and to quickly adapt to different ecological niches. There is increasing evidence that these survival strategies are only displayed by part of a population at any given time, a phenomenon described as a bistability, and that this is due to epigenetic variation (Rauch \& Bar-Yam, 2004). This epigenetic variation results in the emergence of phenotypic traits that manifest themselves as subtypes within an isogenic population, where such variation provides a mechanism to enable rapid exploitation of environmental opportunities or response to stresses, sometimes referred to as 'bet-hedging' (Veening et al., 2008).

Abbreviations: AMC, 7-amido-4-methylcoumarin; B-Arg-AMC, $\alpha N$ benzoyl-L-arginine-7-amido-4-methylcoumarin; boc-Val-Leu-Lys-AMC, $t$-butyloxycarbonyl-Val-Leu-Lys-7-amido-4-methylcoumarin; OSCC, oral squamous cell carcinoma; TLCK, $N$-p-tosyl-L-lysine chloromethyl ketone.

A supplementary table, showing the primers used for RT-PCR, and supplementary figures, data tables and raw data, are available with the online version of this paper.

The microarray data discussed in this paper are available from the $\mathrm{NCBI}$ Gene Expression Omnibus (GEO) under accession number GSE23021.
Porphyromonas gingivalis is a Gram-negative anaerobic bacillus that has been strongly implicated in the pathogenesis of periodontal diseases (Socransky et al., 1998). The organism produces a range of virulence factors, including fimbriae (implicated in attachment and colonization; Nakayama et al., 1996a; Yoshimura et al., 2009), proteases known as gingipains (implicated in tissue destruction; Pike et al., 1996; Kadowaki et al., 1998; Curtis et al., 2001) and lipopolysaccharide (Darveau et al., 2004). In addition, there have been a number of reports demonstrating the ability of the organism to invade and survive within epithelial cells (Lamont et al., 1992, 1995; Duncan et al., 1993; Madianos et al., 1996). Such invasive ability is considered to be a virulence trait because it may represent a strategy whereby the organism could evade the local host defences and so persist at an infection site. The mechanism of epithelial cell invasion by $P$. gingivalis has not been fully elucidated but has been suggested to depend upon the interaction of bacterial fimbriae with cell-associated fibronectin and the fibronectin-binding integrin $\alpha_{5} \beta_{1}$ (Tsuda et al., 2008; Yilmaz et al., 2002; Yilmaz, 2008). However, there have also been reports that strains with identical fimbriation characteristics vary in their invasive ability (Dorn et al., 2000; Duncan et al., 1993; Hamada et al., 1994; Eick et al., 2006), indicating uncertainty about 
the mechanisms employed by all strains of $P$. gingivalis and that more than one mechanism may be operating.

Since bistable populations give rise to subtypes exhibiting different phenotypes, we asked whether those $P$. gingivalis cells that become successfully internalized in epithelial cells represent an invasive subpopulation as part of a natural bistable system. Here we present evidence for the existence of highly invasive and poorly invasive subpopulations in cultures of two strains of $P$. gingivalis. We demonstrate differences in gene expression between the two subtypes and show that the surface-associated protease enzyme complex Arg-gingipain (encoded by $\operatorname{rgp} A: B$ ) (Nakayama et al., 1995, 1996b; Curtis et al., 2001) influences invasion and is a key feature of the bistable phenotype that we observe.

\section{METHODS}

Bacteria and culture conditions. $P$. gingivalis strains NCTC 11834, W50, E8 (isogenic $\operatorname{rgp} A$ : $r g p B$ mutant of strain W50), W501 (isogenic $\operatorname{rgpA}$ strain of W50), D7 (isogenic $r g p B$ mutant of W50) and K1A (isogenic $\mathrm{kgp}$ mutant of W50) were used. All W50 mutants were kindly supplied by M. Curtis, Blizard Institute of Cell and Molecular Science, Barts and The London School of Medicine and Dentistry, London, UK. All P. gingivalis strains (NCTC 11834, W50, E8, D7, W501 and K1A) were grown and maintained on Fastidious Anaerobe Agar (FA; Lab M) supplemented with $5 \%$ horse blood (Oxoid) in an anaerobic cabinet with an atmosphere of $10 \% \mathrm{H}_{2}, 10 \% \mathrm{CO}_{2}$ and $80 \% \mathrm{~N}_{2}$ at $37{ }^{\circ} \mathrm{C}$. The bacteria were subcultured 2 days prior to the start of an experiment.

Epithelial cell culture. The oral squamous cell carcinoma (OSCC) cell line H357 (kindly supplied by Professor S. Prime, University of Bristol) was grown and maintained in keratinocyte growth medium (KGM) containing: Dulbecco's modified Eagle's medium and Ham's F12 medium $(3: 1)$ with $10 \%$ fetal bovine serum, penicillin (100 IU $\left.\mathrm{ml}^{-1}\right)$, streptomycin $\left(100 \mathrm{IU} \mathrm{ml}^{-1}\right)$, amphotericin B $\left(2.5 \mu \mathrm{g} \mathrm{ml}^{-1}\right)$ (all from Invitrogen), epidermal growth factor $\left(10 \mathrm{ng} \mathrm{ml}^{-1}\right)$, adenine $(0.18 \mathrm{mM})$, cholera toxin $(1 \mathrm{nM})$, hydrocortisone $\left(5 \mu \mathrm{g} \mathrm{ml}^{-1}\right)$ and insulin $\left(5 \mu \mathrm{g} \mathrm{ml}^{-1}\right)$ (all from Sigma) in an atmosphere containing $5 \% \mathrm{CO}_{2}$ at $37^{\circ} \mathrm{C}$. Cell monolayers were grown under submerged conditions and were checked by cytokeratin 13 staining, a marker of non-keratinization. Confluent stock cultures were trypsinized, adjusted to approximately $5 \times 10^{3}$ cells $\mathrm{ml}^{-1}$ and seeded into 12 well plates (Nunc, $1 \mathrm{ml}$ per well) $48 \mathrm{~h}$ prior to an experiment. These epithelial cells were generally semi-confluent $\left(10^{5}\right.$ cells per well $)$ after this time.

Primary cultures of gingival epithelial cells were obtained from gingival biopsies taken as part of elective treatment and had full approval from the Sheffield Research Ethics Committee. Cells were grown and passaged as described above for the H357 cell line. The cells were incubated for a further $48 \mathrm{~h}$ until there were approximately $10^{5}$ cells per well prior to use in an invasion assay (see below). Again, monolayers were grown under submerged conditions, which prevented keratinization, and this was checked by cytokeratin 13 staining.

Standard antibiotic protection assay. Bacteria were harvested from $48 \mathrm{~h}$-grown agar plates, washed three times in PBS and then suspended in serum-free medium [SFM; Dulbecco's modified Eagle's medium and Ham's F-12 medium $(3: 1)$ without supplement] and adjusted to $10^{7}$ bacteria $\mathrm{ml}^{-1}$. The inoculum concentration was confirmed by viable counting. Confluent H357 cell monolayers were washed three times with SFM and incubated with bacterial suspensions in $5 \% \mathrm{CO}_{2}$ at $37{ }^{\circ} \mathrm{C}$ for $90 \mathrm{~min}$ at an m.o.i. of $1: 100$. Non-adherent bacteria were then removed by washing with SFM while cell surface-bound bacteria were killed with metronidazole $\left(200 \mu \mathrm{g} \mathrm{ml}^{-1}, 60 \mathrm{~min}\right)$. After removal of antibiotic, the internalized bacteria were released by osmotic lysis in sterile distilled water with scraping. Lysates were serially diluted and plated in duplicate, and the resultant colonies were counted after 4 days of growth. All experiments were performed in triplicate, and data presented are the mean $\pm \mathrm{SD}$ invasion as a proportion of the number of viable bacteria in the starting suspension that had been incubated aerobically in parallel with the invasion culture.

Reinvasion assay. As an initial approach to test for subtypes we devised a two-round invasion assay (see schematic in Fig. 1a) in which $P$. gingivalis strains and mutants were allowed to invade H357 keratinocytes or primary keratinocytes as above (round 1), the noninternalized bacteria were killed with metronidazole and the internalized bacteria released by osmotic lysis and cell scraping. These released bacteria were then adjusted in number and applied to a second set of keratinocytes (round 2) at an m.o.i. of 100:1. This m.o.i. was initially achieved by performing the first-round invasion on a large flask culture of keratinocytes and then performing the second round on a small keratinocyte culture (see data in Fig. 1b). Once we had established that this was a stable phenotype (see Results), we cultured the round 1-released bacteria on FA-blood agar for the minimum period and then used these bacteria for the second round of invasion. Following the round 2 invasion (90 $\mathrm{min}$ ), noninternalized bacteria were killed with metronidazole and internalized bacteria then released by osmotic lysis as above.

Proteinase assays. Arginine-specific and lysine-specific protease activities of the various strains were assessed in a microplate proteinase assay performed using fluorogenic substrates. For wholecell assays, bacteria were grown in supplemented Brain Heart Infusion (BHI; Oxoid) broth instead of on plates for reasons of convenience and consistency of growth phase, and because we wished to assay supernatant protease activities as well as cell-associated levels. Bacteria were then harvested by centrifugation and resuspended in PBS to $\mathrm{OD}_{600} 1.0\left(\sim 10^{9}\right.$ bacteria $)$. Aliquouts of $100 \mu \mathrm{l}$ were then added to either $\alpha N$-benzoyl-L-arginine-7-amido-4-methylcoumarin (B-ArgAMC) for Arg-proteinase activity $\left(37{ }^{\circ} \mathrm{C}\right.$ for $\left.15 \mathrm{~min}\right)$ or $t$-butyloxycarbonyl-Val-Leu-Lys-7-amido-4-methylcoumarin (boc-Val-LeuLys-AMC) for Lys-proteinase activity $\left(40{ }^{\circ} \mathrm{C}\right.$ for $10 \mathrm{~min}$ ), both at $200 \mu \mathrm{M}$ in PBS (Chen et al., 2001). Protease reactions were terminated by the addition of $N$-p-tosyl-L-lysine chloromethyl ketone (TLCK; $500 \mu \mathrm{M}$ ). Released 7-amido-4-methylcoumarin (AMC; $10 \mu \mathrm{M}$ ) was measured with a fluorimeter [microplate reader (POLARstar, BMG Labtech)] with excitation and emission wavelengths of 365 and $460 \mathrm{~nm}$, respectively. Assays were carried out in triplicate and were repeated at least twice with independent cultures.

For the supernatant assay the same procedure was followed except that cell densities were adjusted to $\mathrm{OD}_{600} 1.0$ with $\mathrm{BHI}$ before centrifugation. Supernatants were then filtered through a sterile syringe filter $(0.45 \mu \mathrm{m}$ pore-size $)$ to remove particulate matter before assaying in the same manner as above.

Stability of the invasive phenotype. $P$. gingivalis NCTC 11834 cells recovered from $\mathrm{H} 357$ cells were cultured on FA-blood agar and then subcultured at 2-day intervals. Each subculture was tested for its ability to invade $\mathrm{H} 357$ cells as described above.

Screening cultures of $\boldsymbol{P}$. gingivalis for protease-deficient variants. $P$. gingivalis NCTC 11834 and W50 cells were collected from FA-blood cultures and separately suspended in PBS. Aliquots 
(a)

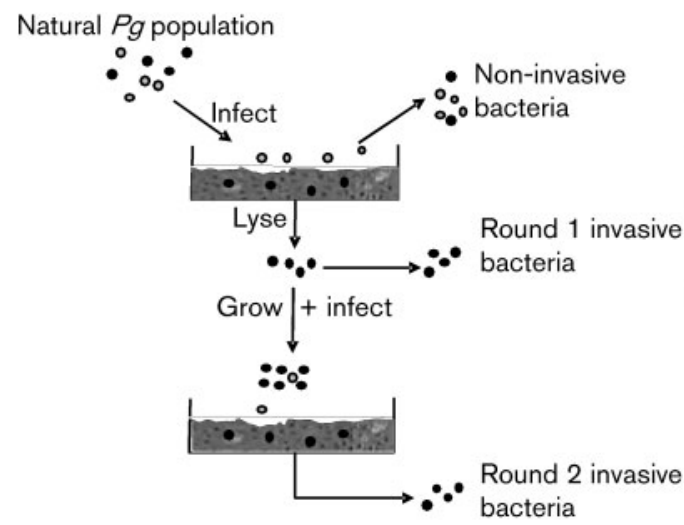

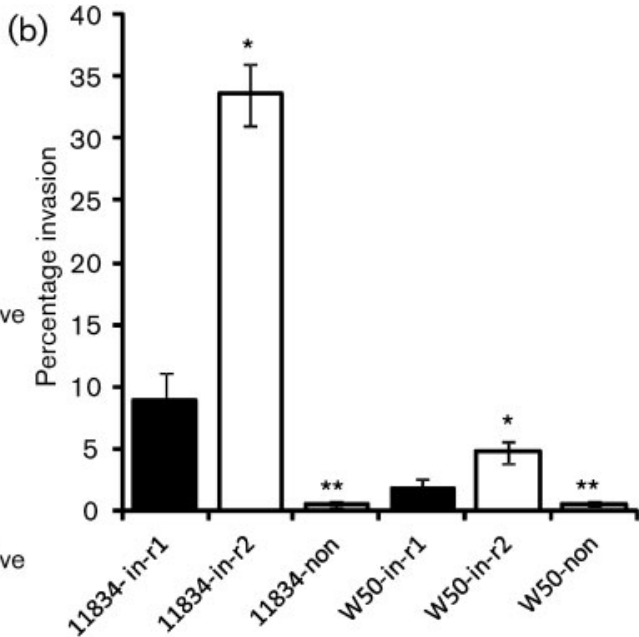

Fig. 1. Enrichment of invasive subpopulations of $P$. gingivalis. (a) Schematic illustrating the invasion assay. OSCC cells (H357) were infected with a natural population of $P$. gingivalis $(P g)$. This was a mixture of invasive (black) and non-invasive (grey) cells. After washing and metronidazole treatment, H357 cells were lysed and internalized bacteria recovered. The round 1 invasive cells were then grown and used to infect fresh $\mathrm{H} 357$ cells. The round 2 invasive cells were then recovered and further enriched for the invasive subtype. (b) Invasive properties of enriched subpopulations. Wild-type $P$. gingivalis NCTC 11834 and W50 were incubated with $\mathrm{H} 357$ cells as described above, and invasion was calculated as a percentage of the starting cell number (11834-in-r1, W50-in-r1). Similarly, non-invasive cells were incubated with H357 cells and invasion was assessed (11834non, W50-non). Round 1 invasive cells were then immediately reintroduced to fresh H357 cells for a second round of invasion (11834-in-r2, W50-in-r2). Experiments were performed in triplicate; error bars, SD. $t$ tests revealed statistically significant differences $(P<0.00003)$ between the natural population $\left(11834 / \mathrm{W} 50\right.$-in-r1) and both invasive $\left(11834 / \mathrm{W} 50\right.$-in-r2) $\left(^{*}\right)$ and non-invasive (11834/W50-non) and invasive (11834/W50-in-r1) $\left(^{* *}\right)$ datasets.

were spread onto FA-blood agar to give approximately 50 colonies per plate. Individual colonies (60) were picked at random, inoculated and cultured in BHI broth supplemented with haemin $\left(5 \mu \mathrm{g} \mathrm{ml} \mathrm{ml}^{-1}\right)$, cysteine $\left(1 \mu \mathrm{g} \mathrm{ml}^{-1}\right)$ and vitamin $\mathrm{K}\left(1 \mu \mathrm{g} \mathrm{ml}^{-1}\right)$, and each isolate was then assayed for arginine protease activity using B-Arg-AMC substrate as above $(200 \mu \mathrm{M}$ in $50 \mathrm{mM}$ Tris buffer, $\mathrm{pH}$ 7.4) (Chen et al., 2001). Selected isolates that showed differing arginine protease activity were individually assessed for their ability to invade H357 cells as described above.

Effect of proteinase inhibitors on cell invasion. $P$. gingivalis NCTC 11834 and W50 wild-type strains $\left(10^{7}\right.$ cells $)$ were either untreated (control) or treated for $30 \mathrm{~min}$ at $4{ }^{\circ} \mathrm{C}$ with the proteinase inhibitor leupeptin $(0.2 \mathrm{mM})$, which displays $100 \%$ inhibition of Arg-gingipain but has no effect on Lys-gingipain activity (data not shown), or with TLCK $(0.5 \mathrm{mM}$ final concentration), which completely inhibits Arg-gingipain while only reducing Lys-gingipain activity by approximately $30 \%$ (data not shown), before being applied to $10^{5} \mathrm{H} 357$ cells. Other aspects of the invasion procedure were as described above.

Genome microarray analysis. Total RNA was extracted from bacteria that had just been recovered from an invasion experiment and cultured for $48 \mathrm{~h}$ on FA-blood agar. Bacteria were harvested and resuspended in TRIzol reagent (Invitrogen) before heating to $95{ }^{\circ} \mathrm{C}$ in the presence of an RNase inhibitor (RNAprotect, Qiagen). The aqueous supernatant was then extracted with phenol/chloroform according to standard methods. Following phase separation and precipitation with 2-propanol, the quality of the RNA was checked by gel electrophoresis. cDNA was prepared by RT-PCR using random hexamer primers and aminoallyl-dUTP. After alkylation, neutralization and purification, the cDNA was labelled with Cy-3 ester and used to probe $P$. gingivalis genomic microarray slides (J. Craig Venter Institute; JCVI). The microarrays consisted of 1907 70-mer oligonucleotides representing 1990 ORFs. The full 70-mer complement was printed four times on the surface of each microarray slide.

Microarray slides were first UV cross-linked, prehybridized in $5 \times$ SSC, $1 \%$ BSA, $0.1 \%$ SDS for $45 \mathrm{~min}$ at $42{ }^{\circ} \mathrm{C}$, then hybridized at $65{ }^{\circ} \mathrm{C}$ overnight. Microarrays were scanned with a GenePix $4000 \mathrm{~B}$ scanner operating at 532 and $635 \mathrm{~nm}$ to excite Cy3 and Cy5, respectively. Data from each fluorescence channel were collected and stored as separate 16-bit TIFF images, and were analysed to calculate the relative expression of each gene using TIGR Spotfinder software (http://www.tm4.org/spotfinder.html).

Briefly, data from six individual experiments were normalized and then analysed using the Spotfinder Software (raw data are available as four supplementary files with the online version of this paper). The data points with a density below 100000 were discarded for analysis according to the manufacturer's recommendations. A cut-off ratio of $1.5: 1$ was used on all the slides. Significance Analysis of Microarrays (SAM) software $\left(\mathrm{TM}_{4}\right.$ software, JCVI) was used to test statistically significant results from the microarray experiments. This statistical analysis involved sorting the change in expression of each gene relative to the SD of all replicates for that gene. Therefore, even genes with a small change were not discounted if the ratios were consistent among all the repeats, thus effectively reducing false-negatives. Falsepositives were also avoided by excluding genes that had poor reproducibility between replicates. In this way, the results from this assay were made more reliable. Spot intensities for all channels were entered into SAM as paired, unlogged values. Delta values were chosen according to the lowest false discovery rate, which for this study was $4.7 \%$. In combination with the 1.5 -fold change, the data 
were analysed, and genes with expression ratios of $\geqslant 3.5$ were considered biologically significant.

RT-PCR. cDNA was generated from $1 \mu \mathrm{g}$ RNA isolated from invasive and poorly invasive $P$. gingivalis NCTC 11834 and W50 and isogenic wild-type strains using MultiScribe Reverse transcriptase (Applied Biosystems), according to the manufacturer's instructions, and genespecific reverse primers (Supplementary Table S1). GoTaq (Promega) was then used to amplify the cDNA with gene-specific primers. Expression of genes of interest was examined by densitometry of ethidium bromide-stained gels using Scion Image (National Institutes of Health; NIH) with normalization to the endogenous $16 \mathrm{~S}$ rDNA control in a semiquantitative assay. The PCR programme was as follows: initial denaturation at $94{ }^{\circ} \mathrm{C}$ for $2 \mathrm{~min}$, then 25 cycles each of $94{ }^{\circ} \mathrm{C}$ for $2 \mathrm{~min}$, annealing at $60{ }^{\circ} \mathrm{C}$ for $30 \mathrm{~s}$, extension at $68{ }^{\circ} \mathrm{C}$ for $2 \mathrm{~min}$ and final extension at $68{ }^{\circ} \mathrm{C}$ for $5 \mathrm{~min}$ in an $\mathrm{MJ}$ thermocycler (Bio-Rad Laboratories).

Sensitivity to hydrogen peroxide. To determine relative sensitivity to oxidative stress, wild-type strains and variants were exposed to hydrogen peroxide. Overnight broth cultures [BHI plus haemin $(5 \mu \mathrm{g}$ $\left.\mathrm{ml}^{-1}\right)$, cysteine $\left(5 \mu \mathrm{g} \mathrm{m} \mathrm{m}^{-1}\right)$ and menadione $\left.\left(200 \mu \mathrm{g} \mathrm{ml}^{-1}\right)\right]$ of $P$. gingivalis NCTC 11834 and W50, wild-type, non-invasive and round 2 invasive types were adjusted to $\mathrm{OD}_{600} 1.0$ in PBS before mixing with $\mathrm{H}_{2} \mathrm{O}_{2}$ at final concentrations ranging from 0 to $3.4 \mathrm{mM}$ in microtitre wells, and were incubated for $90 \mathrm{~min}$ at room temperature. Suspensions were then serially diluted and c.f.u. in aliquots was counted after 2 days growth on FA-blood agar incubated anaerobically.

\section{RESULTS}

\section{Natural populations of $\boldsymbol{P}$. gingivalis contain a subpopulation with increased invasive capability}

As a starting point to establish whether bistable subpopulations of $P$. gingivalis exist and whether they vary in their ability to invade epithelial cells, we devised a two-stage antibiotic protection assay which would allow enrichment of an invasive subpopulation if it existed (Fig. 1a). In this assay, cells of two strains of $P$. gingivalis (NCTC 11834 and W50) that had been internalized and then released from an initial set of oral keratinocytes (round 1) were immediately collected and allowed to invade a second, fresh set of oral keratinocytes (round 2). Bacteria that had been internalized a second time were then collected and analysed further by viable plate counting. Bacteria that remained in the supernatant during the first round of infection were also collected and analysed further for invasive capability. In each case the number of recovered bacteria was determined by viable counting and expressed as a percentage of the original inoculum. During the development of this assay system we also established that the metronidazole killing step was effective at killing all external $P$. gingivalis cells during the time-course of the experiment (data not shown).

In order to examine the influence of fimbriae on bacterial invasion and to establish that any bistability was not strainspecific, we utilized two well-characterized strains of $P$. gingivalis, NCTC 11834 and W50. Strain W50 possesses short fimbriae that are few in number (Sojar et al., 1997), whereas NCTC 11834 has more fimbriae, and in our initial invasion experiments we observed that strain NCTC 11834 invaded an OSCC cell line (H357) at a higher level than strain W50 ( $\sim 9 \%$ vs $2 \%$; see Fig. $1 \mathrm{~b}$, in-r1). This is in agreement with other published data that used $\mathrm{KB}$ cells (Dorn et al., 2000; Eick et al., 2006; Houalet-Jeanne et al., 2001), and similar levels of invasion have been reported using normal oral keratinocytes (Lamont et al., 1995). When the invasion levels of the recovered bacteria were analysed after a second round of invasion with fresh cells we observed an increase in the percentage of bacteria able to invade the OSCC cells for both strains of over threefold (Fig. 1b, in-r2). Conversely, those cells that did not invade in the first round of infection (remaining in the supernatant) showed a lower percentage invasion when reintroduced to epithelial cells than either the original population as a whole or the round 2 invasive cells by a factor of 10 30-fold (Fig. 1b, non). We also performed this experiment using primary normal oral keratinocytes with essentially identical results, and we showed that both these cells and the H357 cells stained suprabasally with cytokeratin 13, a marker of non-keratinization (data not shown) (Maeda et al., 1994).

These data suggest that we had enriched for a subpopulation of bacteria in the original natural population that was more able to invade or survive within OSCC cells. It should be emphasized that the antibiotic protection assay actually measures the sum of two processes, cell invasion and intracellular survival. Our data are not able to distinguish between these two events.

\section{Stability of the invasive phenotype}

In order to test the stability of the phenotypic variants identified within the $P$. gingivalis populations we subcultured the NCTC 11834 and W50 invasive subtype cells released from a second-round invasion of $\mathrm{H} 357$ cells every 2 days on FA-blood agar. Each subculture was then tested for invasive capability as before. As shown in Fig. 2, a statistically significant elevated invasive capability $(P<0.05)$ was retained in culture on laboratory medium for 2-3 passages before a return to baseline levels. Given that the doubling time of $P$. gingivalis is approximately $6 \mathrm{~h}$ on artificial media (Madianos et al., 1996), this represents around 12-16 generations over two passages. Therefore, we appear to have genuinely enriched for a distinct subpopulation of $P$. gingivalis that is stable over several replicative cycles.

\section{Cell-associated rgp protease activity contributes to the $P$. gingivalis invasive subtype phenotype}

The best-characterized virulence determinants of the oral pathogen $P$. gingivalis are the extracellular arginine-specific proteases RgpA and RgpB and the lysine-specific protease Kgp, which are collectively known as gingipains (Nakayama et al., 1996b; Fitzpatrick et al., 2009; Kadowaki et al., 2007). There is much evidence for the role of these proteases in $P$. 

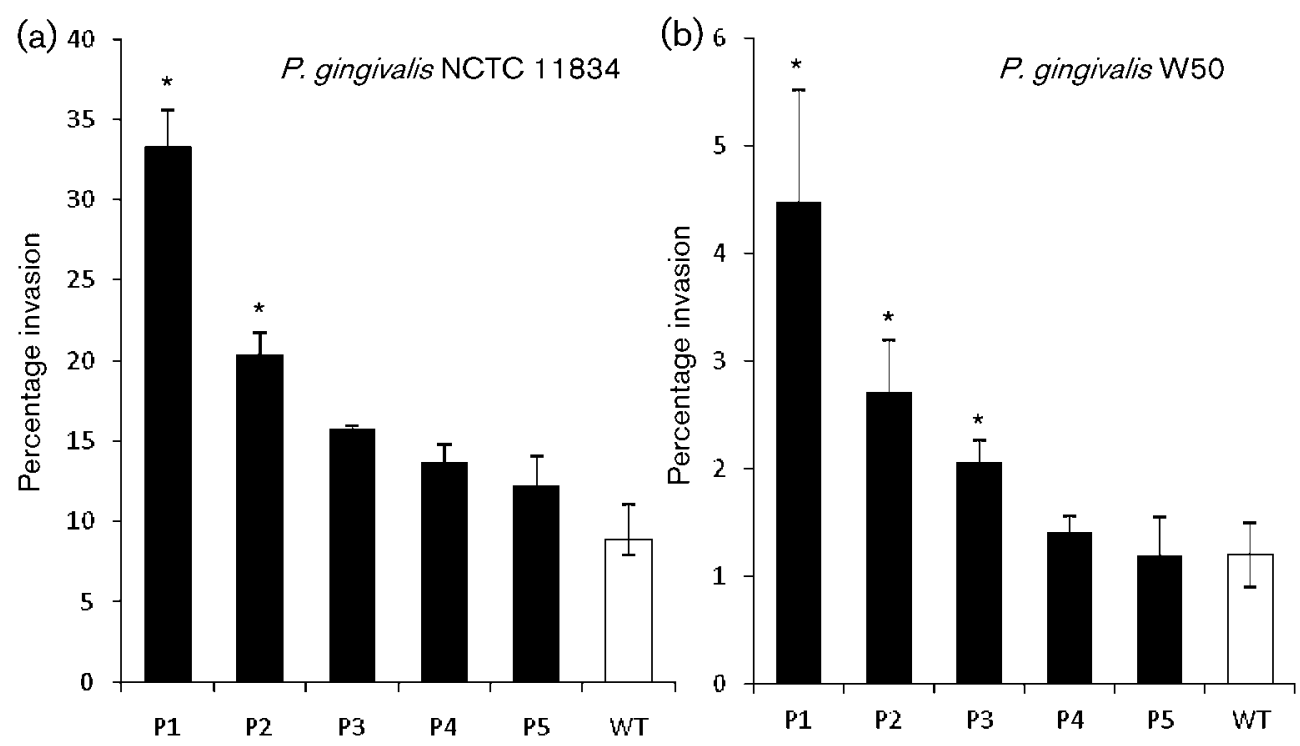

Fig. 2. Stability of the invasive subpopulations. Invasive $P$. gingivalis cells of strains NCTC 11834 (a) and W50 (b) recovered after two rounds of invasion were passaged every 2 days on FA agar for five passages (P1-P5), and invasiveness was assessed as above. Experiments were performed in triplicate; error bars, SD. $t$ tests revealed that invasion rates were higher than wild-type at statistically significant levels $(P<0.05)$ for NCTC 11834 wild-type $(W T)$ versus P1 and P2 and for W50 wild-type (WT) versus $\mathrm{P} 1, \mathrm{P} 2$ and $\mathrm{P} 3$, as indicated by asterisks.

gingivalis pathogenicity and more recently for their role in cell invasion (Boisvert \& Duncan, 2008; Fitzpatrick et al., 2009; Chen \& Duncan, 2004). In light of their importance in this process we decided to examine whether the levels of these proteases might be altered in the invasive and noninvasive subtypes compared with isogenic wild-type strains.

When the cell-associated protease activity of the wild-type and two subtypes of $P$. gingivalis NCTC 11834 was investigated using the arginine-specific substrate B-ArgAMC and the lysine-specific substrate boc-Val-Leu-LysAMC, the invasive subtype showed a statistically significant reduction in cell-associated arginine-specific protease activity of approximately fivefold for NCTC 11834 compared with the wild-type population (Fig. 3a). Strain W50 showed the same trend but less strikingly so with a decrease of only 1.6-fold (Fig. 3a); however, taken together the trend was downward for both strains. In contrast, the cell-associated Arg-protease activity data for the non-invasive subtype compared with the wild-type were inconsistent, with W50 showing a slightly increased activity of 1.5 -fold, and NCTC 11834 a level reduced by a similar factor (Fig. 3a). When we examined the cell-associated Lys-specific protease activity of the invasive subtype we observed higher values, with a 1.4fold increase for NCTC 11834 and 1.8-fold in W50 (Fig. 3b).

When the secreted or supernatant Arg-protease activities were examined they were largely unchanged for the three subtypes (Fig. 3) of strain NCTC 11834, although there was a small (1.2-fold) reduction in secreted activity for the invasive subtype of strain W50, the significance of which was unclear. In contrast, the Lys-protease activities in the supernatant were again increased in the invasive subtypes (Fig. 3b). Taken together, the data indicate that the total level of protease (Arg- and Lys-gingipains) in the invasive subtype was only slightly lower than that in the noninvasive subtype in the two strains, but that the cellassociated Arg-gingipain was lower and the Lys-gingipain was higher in the invasive types of both strains. These data suggest that both gingipain proteases influence the invasive capabilities of our invasive subtype.

To investigate further the putative roles of the arginineand lysine-specific protease activities in invasion, we compared the invasive capability of wild-type $P$. gingivalis W50 with that of isogenic W50 strains containing null mutations in the genes encoding the Arg-protease and Lysprotease ( $\triangle r g p A B$ and $\Delta k g p$, provided by M. Curtis, Barts and The London School of Medicine and Dentistry). The ability of the $\Delta k g p$ strain to invade $\mathrm{H} 357$ cells was unchanged compared with wild-type W50, but the invasive capability of the $\triangle \operatorname{rgp} A B$ strain increased approximately fourfold above wild-type levels (Fig. 4a). These data suggest that it is the reduction in Arg-protease activity that we observed in the invasive subtypes that is most important in the invasive properties in oral epithelial cells, while the influence of Lys-protease activity is unclear.

To confirm this observation and that of reduced Arggingipain cell-associated protease activity, we pretreated wildtype populations of the $P$. gingivalis strains NCTC 11834 and W50 with the protease inhibitors leupeptin (Fig. 4b) and TLCK (Supplementary Fig. S5), with essentially identical results. Both of these inhibitors have been shown to inhibit 

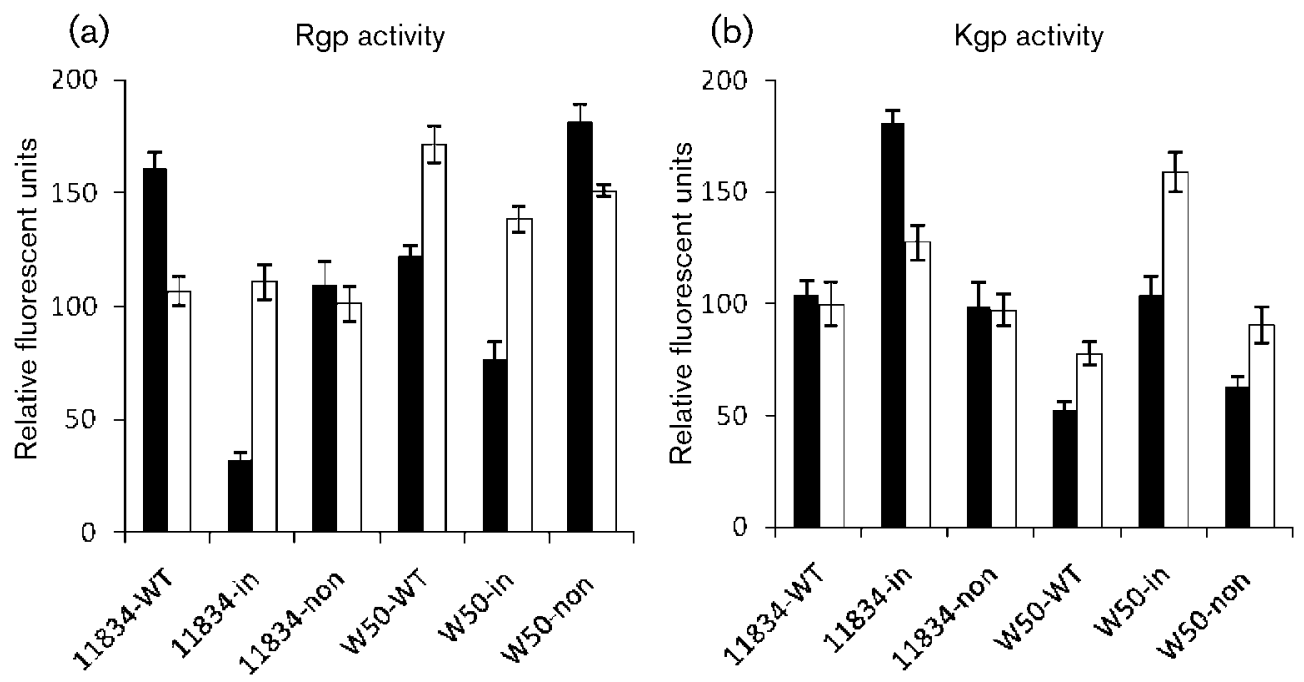

Fig. 3. Whole-cell (filled bars) and supernatant (open bars) protease (Rgp and Kgp) activities. (a) Arg-gingipain (Rgp) activities of wild-type (WT), invasive (in) and non-invasive (non) subtypes of $P$. gingivalis NCTC 11834 and W50. Data are means of triplicate experiments; error bars, SD. Data are expressed as relative fluorescent units (measured in a plate reader with excitation and emission wavelengths of 365 and $460 \mathrm{~nm}$, respectively) for release of AMC from B-Arg-AMC. $t$ tests showed significant differences $(P<0.05)$ between invasive and wild-type strains and invasive versus non-invasive for all whole-cell samples (W50 and NCTC 11834). For supernatant activities, only W50 wild-type versus invasive and non-invasive strains were statistically significant. (b) Lys-gingipain (Kgp) activities of wild-type (WT), invasive (in) and non-invasive (non) subtypes of $P$. gingivalis NCTC 11834 or W50. Data are means of triplicate experiments; error bars, SD. Data are expressed as relative fluorescent units for release of AMC from boc-Val-Leu-Lys-AMC. $t$ tests showed significant differences $(P<0.05)$ between wild-type and invasive strains (W50 and NCTC 11834) and invasive and non-invasive strains (W50 and NCTC 11834) for whole cells and supernatants.

Arg-protease activity (Potempa et al., 1997) and we confirmed this here also (data not shown). Inhibition with leupeptin increased the invasive ability of $P$. gingivalis approximately fivefold (Fig. $4 \mathrm{~b}$ ). Together these data suggest that at least part of the mechanism by which the invasive subtypes exhibit increased invasive ability is associated with downregulation of cell-associated protease activity, specifically the arginine gingipain activity.

If our hypothesis is correct that Arg-protease activity is central to this invasive bistability then it would be predicted that the invasive capability of a null $\operatorname{rgp} A: B$ mutant cannot be enhanced by passage through epithelial cells. To test this we performed the two-round invasion assay described above using the W50 $\triangle \operatorname{rgp} A B$ strain and showed that while an invasive subtype exists within a population of W50 and W50 $\Delta \mathrm{kg}$, there is no further enhancement of invasion by passage of the W50 $\operatorname{rgp} A B$ strain (Fig. 5). This strongly indicates that it is the arginine protease activity that is key to the presence of bistable invasive populations of $P$. gingivalis.

\section{Isolation of an invasive subpopulation by screening for Arg-protease activity}

Since arginine-specific protease activity was decreased in the $P$. gingivalis invasive subtypes (Fig. 3 ) and since the $\Delta r g p A: B$ knockout mutant showed enhanced invasion compared with the parent strain W50, we reasoned that we might be able to isolate invasive subpopulations from a natural population by screening and isolating clonal lines that showed low cell-associated Arg-protease activity. To achieve this, 30 separate colonies of each of the two $P$. gingivalis wild-type strains were screened for variants expressing reduced levels of Arg-protease activity using a fluorescent substrate. Colonies were classified as low protease if the fluorescence activity was $<20 \%$ of the mean level of the population of colonies. Of the 30 colonies of each strain screened, four were found from each pool that showed reduced Arg-protease activity in the assay.

The four low protease isolates, along with four 'normal' protease isolates, for each of the two strains, were then analysed for their ability to invade $\mathrm{H} 357$ cells using the standard invasion assay described above. The low protease type showed higher levels of invasion [37\% for NCTC 11834 (Fig. 6a) and $5 \%$ for W50 (Fig. 6b)] than the normal protease type ( $9 \%$ for NCTC 11834 and $1 \%$ for W50) (Fig. 6), indicating an inverse correlation between protease activity and invasive capability. These data show that two phenotypic subtypes with differing protease expression levels exist within a normal population and that it is possible to isolate an invasive subtype of $P$. gingivalis by screening for protease activity. It also confirmed the strong link between this enzyme activity and invasion. 
(a)

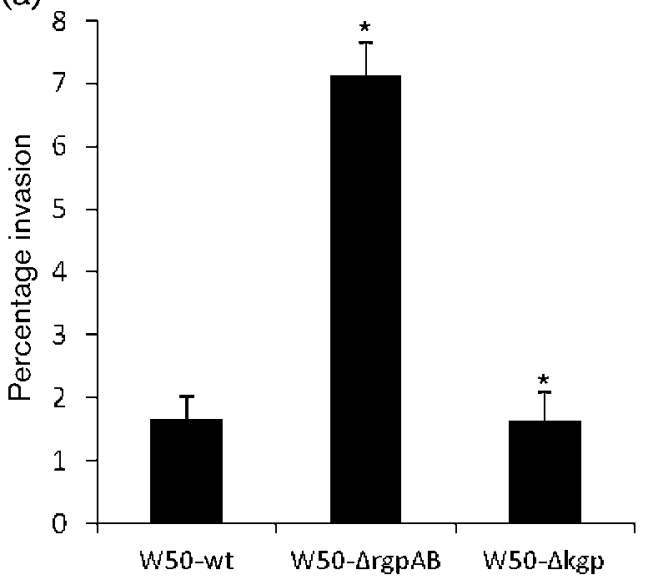

(b)

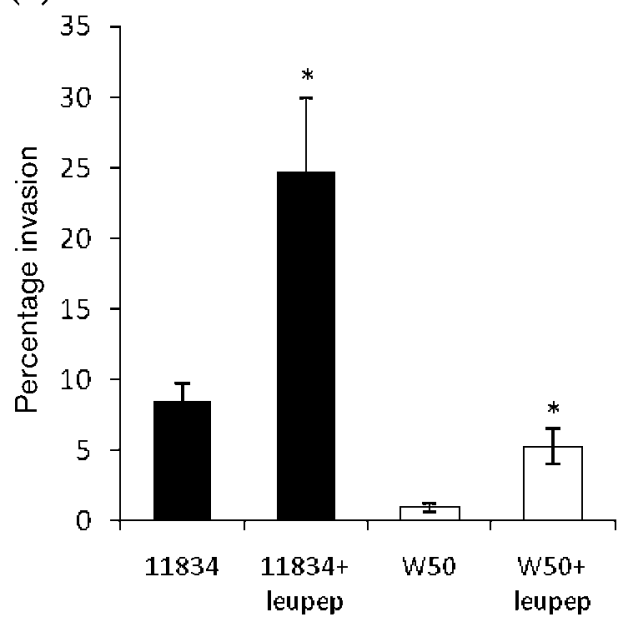

Fig. 4. Influence of protease activity on cell invasion of $P$. gingivalis. (a) Invasion of H357 cells by $P$. gingivalis W50 (wt) and isogenic protease gene mutants W50-E8 $\Delta r g p A: B$ and W50-K1A $\Delta$ kgp (kindly supplied by M. Curtis, Barts and The London School of Medicine and Dentistry). Means of three experiments are shown; error bars, SD. $t$ tests revealed statistically significant differences between the wild-type and $\Delta r g p$ strains $(P<0.00001)$ but not between the wild-type and $\Delta$ kgp strains. (b) Effect of the protease inhibitor leupeptin on cell invasion. $P$. gingivalis NCTC 11834 and W50 wild-type strains $\left(1 \times 10^{7}\right.$ cells $)$ were either untreated or preincubated with the protease inhibitor leupeptin $(0.2 \mathrm{mM})$ for $30 \mathrm{~min}$ at $4{ }^{\circ} \mathrm{C}$ before being applied to $1 \times 10^{5}$ H357 cells. Means of three experiments are shown; error bars, SD. $t$ tests revealed statistically significant differences $(P<0.0002)$ between treated and untreated samples for both strains (asterisks).

\section{Gene expression analysis of the two subtypes}

So far we have presented data illustrating two methods for isolating subpopulations of $P$. gingivalis strains NCTC 11834 and W50 that display an increased ability to invade OSCC cell lines and which have concomitant low argininespecific protease activity. We therefore wanted to investigate global gene expression of invasive and non-invasive and normal and low Arg-protease isolates using the $P$. gingivalis microarray described above. This enabled us to establish whether the two populations shared signature gene expression changes that might be crucial to the invasive capability of this bacterium.

In order to prepare sufficient mRNA for the microarray experiments, and since we have shown that the invasive phenotype is stable over a number of generations, we prepared mRNA from the first culture of invasive bacteria on agar plates and compared the gene expression with corresponding non-invasive bacteria from the same experiment. It was not possible to isolate enough mRNA for microarray analysis from the bacteria that were directly liberated from epithelial cells.

Comparison of the microarray data for the invasive population with those for the non-invasive population revealed 139 and 136 genes that were either up- or downregulated $>3.5$-fold in strains NCTC 11834 and W50, respectively. Of these genes, $94 \%$ were shared between the two strains, illustrating the reliability of the data and RNA collection method. This is emphasized by examination of the predicted cellular location and function of these gene products (Supplementary Figs S1a, b and S2), which are detailed in the supplementary files. Groups of regulated genes of particular note include those whose products are involved in resistance to various forms of stress [uspA (PG0245), clpB (PG1118), groESL (PG0520-1), sodB (PG1545) and oxyR (PG0270)], iron uptake [feoB-1 (PG1043), hmuYR (PG1551) and fur (PG0465)], and the gingipain $r g p A$ (up 17-fold, PG2024) and $\operatorname{rgpB}$ genes (down 3.6-fold, PG0506). One of the gene expression changes that was more difficult to reconcile with the observed phenotypes was that of $r g p A$. This gene was increased in expression in the invasive types of both NCTC 11834 and W50 strains (although it did not change in the low proteinase type), yet the overall Arg-protease level was not significantly increased. We did find that the cell-associated protease was reduced in the invasive types of both strains, although the cell-free protease level was similar to that of the wild-type population. Currently we cannot explain these findings with certainty but they may reflect differences in posttranslational processing of the gingipains in these subtypes or differing roles for the RgpA and RgpB enzymes in these different situations. For example, the gingipains must be correctly secreted, glycosylated, folded and proteolytically processed for full function, all of which influence their activity independently of their expression levels. In particular, it has been reported that RgpB activity influences the glycosylation and stability of RgpA (Rangarajan et al., 2005). 


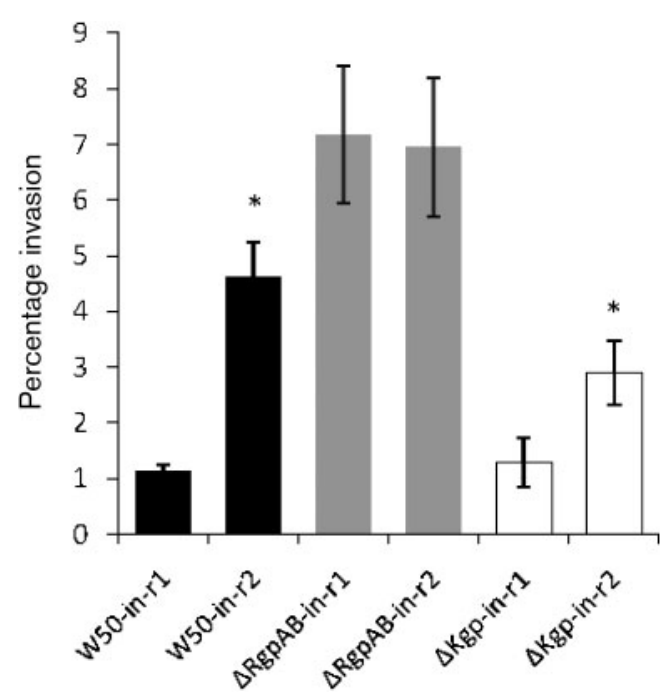

Fig. 5. Influence of rgp and kgp mutations on invasive population enrichment. Wild-type W50 or isogenic $\Delta \operatorname{rgp} A B$ and $\Delta k g p$ strains were incubated with $\mathrm{H} 357$ OSCC cells as described above and percentage invasion values were calculated (-in-r1). After outgrowth on agar plates these cells were reintroduced to fresh $\mathrm{H} 357$ cells for a second round of invasion (-in-r2). Experiments were made in triplicate; error bars, SD. $t$ tests revealed statistically significant differences between round 1 and round 2 samples for both wild-type $(P<0.012)$ and $\Delta k g p(P<0.009)$ strains, as indicated by asterisks.

In order to examine the idea that RgpB plays a greater role than RgpA in the highly invasive phenotypes that we had isolated, we tested the invasion rates of individual $\operatorname{rgp} A$ and $r g p B$ mutant strains in our antibiotic protection assay. Fig. 7 illustrates that invasion by the $r g p B$ mutant was approximately $30 \%$ higher than that by the rgpA mutant and approximately fourfold higher than wild-type. Whilst illustrating that the picture is not a simple one, these data indicate that RgpB-dependent protease activity may be particularly important.

Given that we could also isolate bistable populations based on their protease activity and that these differed in invasive capability, we similarly compared gene expression between the normal (control) and low proteinase isolates by employing microarray analysis. The results are summarized in Supplementary Figs S1 and S3 (with detailed results in Supplementary Table S2). Again, the reproducibility between strains W50 and NCTC 11834 was high, with $99 \%$ of the genes up- or downregulated by greater than 3.5-fold shared between the two strains. Also, several stressassociated proteins $(\operatorname{sod} B, c l p B, \quad \operatorname{cl} C, \quad \operatorname{oxy} R)$ and iron transport-related genes $(h m u Y, h m u R, f e o B-1$, fur $)$ were upregulated. Again, $\operatorname{rgp} B$ was downregulated 3.6-fold, while $\operatorname{rgp} A$ was not found to be significantly up- or downregulated in this dataset, once more indicating that it may be the $\operatorname{rgp} B$ gene product that is more important in this phenomenon. When these data are taken together with the invasive/non-invasive data, the similarity of the subpopulations that were isolated for each strain is apparent.

To compare the gene expression of the two subpopulation types in more detail, we interrogated our datasets to determine which genes were up- or downregulated in the two sets of microarray experiments, i.e. invasive versus non-invasive and high versus low proteinase subtypes. In (a)

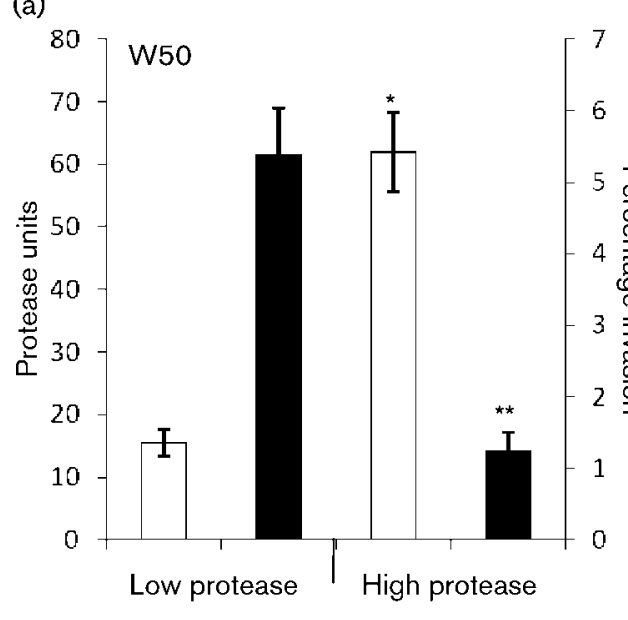

(b)

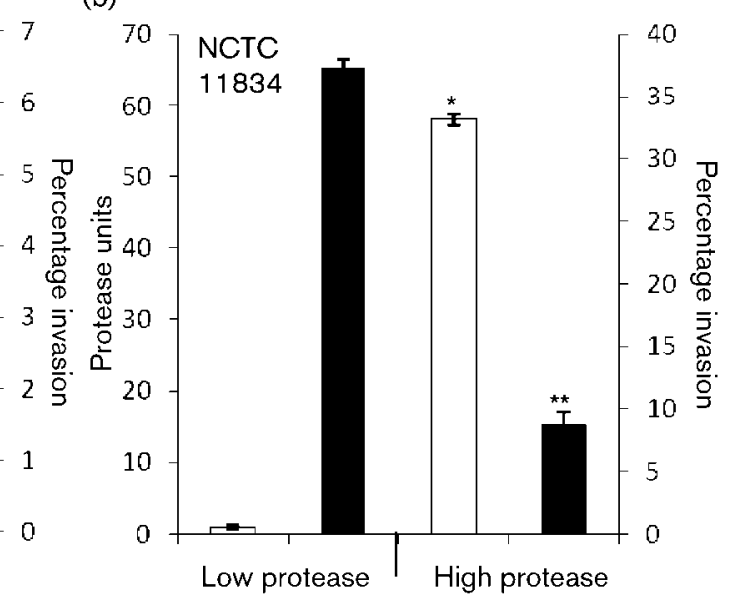

Fig. 6. Invasive capability of low protease isolates of (a) P. gingivalis W50 and (b) NCTC 11834. Four low and four high protease colonies (arbitrary fluorescence units shown, with B-Arg-AMC as substrate) were examined for invasive capability with H357 cells. Data from each set of four colonies were pooled and are shown here. Experiments were performed in triplicate; error bars, SD. $t$ tests showed significant differences between protease levels of the two types and invasion levels of the two types ( ${ }^{*}$ and ${ }^{* *}$, respectively, $P<0.05$ ). Open bars, protease activity; filled bars, invasion. 


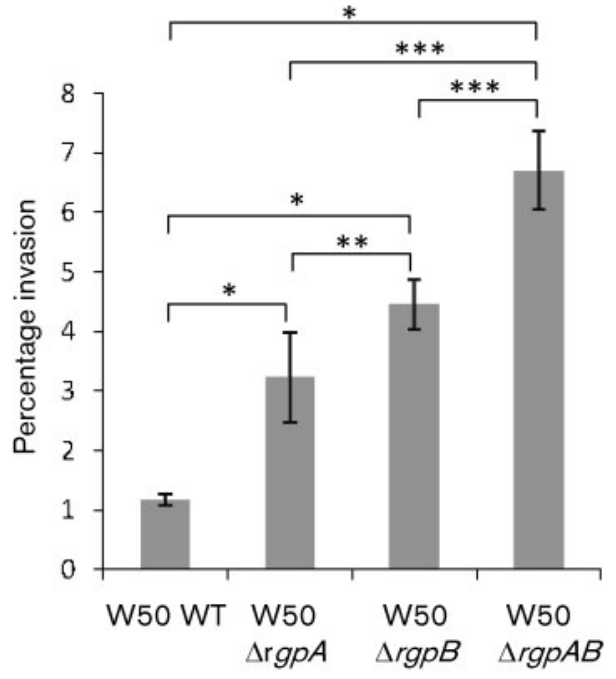

Fig. 7. Invasion of $\mathrm{H} 357$ cells by $P$. gingivalis $\mathrm{W} 50$ and isogenic individual protease gene mutants W50- $\operatorname{rgp} A$ (W501), W50$\triangle \operatorname{rgp} B(\mathrm{D} 7)$ and W50- $\operatorname{rgp} A B(\mathrm{E} 8)$ (kindly supplied by M. Curtis, Barts and The London School of Medicine and Dentistry). Means of three experiments are shown; error bars, SD. $t$ tests revealed statistically significant differences between the wild-type and mutant strains $\left(P<0.01,{ }^{*}\right)$, between the $\operatorname{rgp} A$ and $\operatorname{rgp} B$ strains $\left(P<0.009,{ }^{* *}\right)$, and between the $\operatorname{rgp} A B$ and $\operatorname{rgp} A / B$ individual strains $\left(P<013,{ }^{\star \star *}\right)$.

total, 19 genes were co-ordinately regulated in all four datasets and are shown in Table 1 . We propose that these are a signature set of genes that are common to these subtypes and influential in cell invasion. They again contain several stress-related genes, including $\operatorname{sodB}$, which is involved in detoxification of oxygen radicals, and $\operatorname{oxy} R$, which has been shown to play a role in control of many other oxygen-related genes. Iron transport is also well represented in the microarray gene dataset, with the haem utilization gene $h m u R$ and the iron transporter $f e o B-1$ upregulated. Interestingly, the $\operatorname{rgp} B$ gingipain gene was downregulated 3.5-fold, suggesting that this is the source of reduced cell-associated protease activity in the invasive subpopulation. Of the five outer membrane protein/ periplasmic proteins in this combined dataset (Table 1), it is striking that the periplasmic chaperone $o m p H$, which aids assembly of several outer membrane proteins, was upregulated. When the other data were analysed, two of its target substrates for assembly, the OmpA homologues (PG0694 and 0695), were also upregulated in three of the four datasets, indicating that OmpA may be an important protein in host interaction.

We also observed upregulation of ftsE (PG2190) and murF (PG1106), which are involved in modulating cell division, although the significance of this was unclear, since we did not observe any differences in cell size or shape between the two phenotypes.
We verified the validity of our microarray data qualitatively by RT-PCR of mRNA samples from the invasive and poorly invasive subtypes of strains W50 and NCTC 11834. The 16S rRNA gene was used as a control, and identical band intensities were obtained from both subtypes (Supplementary Fig. S4). The RT-PCR for the hmuY, $\operatorname{rgp} A$, $\operatorname{rgp} B, \operatorname{clp} B$ and $\operatorname{oxyR}$ genes qualitatively confirmed the changes in expression seen using the microarray.

\section{The invasive subpopulation displays increased oxidative stress resistance}

As highlighted above, the microarray data indicated that in addition to alterations in levels of protease there are several genetic changes in both the invasive and the low protease subtypes. Of these gene expression changes, it is striking that a number of stress proteins, particularly oxidative stress genes such as $\operatorname{oxy} R$ and $\operatorname{sodB}$, are altered. We tested this by using hydrogen peroxide as a form of oxidative stress. The data in Fig. 8 show that the invasive and low proteinase subtypes are two- to threefold more resistant to challenge with hydrogen peroxide than the corresponding wild-type and non-invasive/high proteinase strains. Such responses were not an artefact of exposure to oxygen during the experimental invasion procedure, since the same two phenotypes were observed when we performed the experiments anaerobically. These data confirm phenotypically the suggestion from the microarray data that a set of genes involved in tolerance to oxidative stress is upregulated in the invasive subpopulations.

\section{DISCUSSION}

Two distinct phenotypes have been recognized within cultured populations of $P$. gingivalis W50 and NCTC 11834 that display different abilities to invade or survive within an epithelial cell line and normal oral keratinocytes. It is possible that the cell-invasive phenotype represents an adaptation in response to the intracellular environment; however, this seems unlikely, as the phenotype was stable for approximately 12-18 generations in agar culture before a mixed invasive phenotype population developed again, and invasive subtypes could also be identified by screening natural populations for the characteristic of low proteinase activity. It seems more likely then that these features represent bistable populations of $P$. gingivalis. Whether the two types of invasive strain represent the same bistable population or two separate variants is not entirely certain, although a significant number of common transcriptomic changes were observed, and their proteinase, $\mathrm{H}_{2} \mathrm{O}_{2}$ resistance and invasion phenotypes were similar.

The bistability phenomenon has been described before in several other organisms (Smits et al., 2006). However, this is the first time such variation has been described in relation to a cell-invasive phenotype. The benefits of such variation to $P$. gingivalis growing in a host might include an enhanced ability of the population to cope with the varied 
Table 1. Regulated genes shared between the high and low invasive/proteinase subtypes, as identified by microarray experiments Abbreviations: OM, outer membrane; CY, cytoplasmic; PP, periplasmic; IM, inner membrane; EC, extracellular.

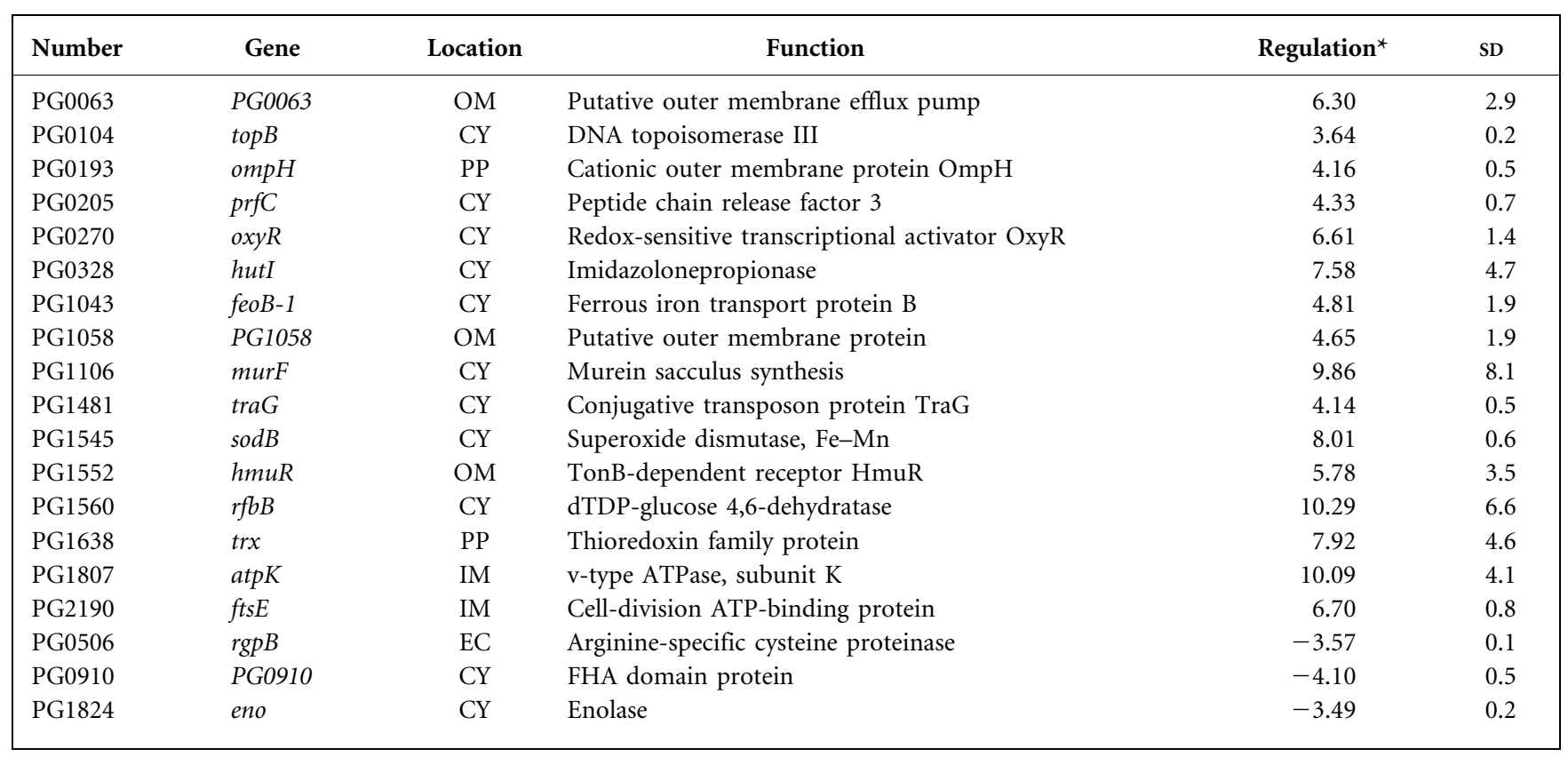

${ }^{*}$ Mean level of regulation between all four datasets.
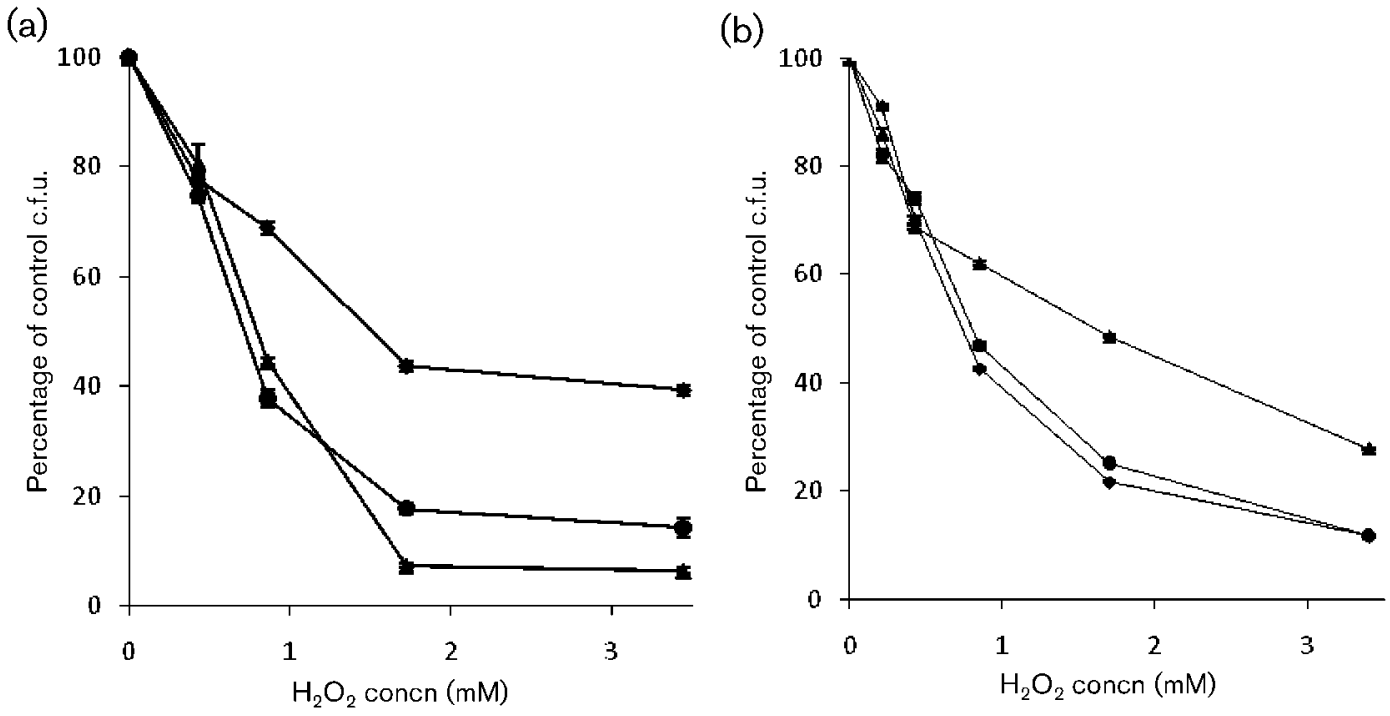

Fig. 8. Increased hydrogen peroxide resistance of invasive (a) and low proteinase (b) subtypes. (a) Wild-type ( $(\bullet)$, invasive ( $\bullet$ ) and non-invasive $(\boldsymbol{\Lambda})$ subtypes; $(\mathrm{b})$ wild-type $(\boldsymbol{\bullet})$, high protease $(\boldsymbol{\nabla})$ and low protease $(\boldsymbol{\Delta})$ subtypes of $P$. gingivalis strain NCTC 11834. Overnight broth cultures were adjusted to $\mathrm{OD}_{600} 1$ in $\mathrm{PBS}$ and mixed with $\mathrm{H}_{2} \mathrm{O}_{2}$ at concentrations ranging from 0 to $3.4 \mathrm{mM}$ before incubation for $90 \mathrm{~min}$ under anaerobic conditions at $37{ }^{\circ} \mathrm{C}$ and plating for viability. Means of triplicate experiments are shown; error bars, SD. $t$ tests revealed that the wild-type and non-invasive data were statistically different from those of the invasive subtype at $P<0.01$ for all concentrations of $\mathrm{H}_{2} \mathrm{O}_{2}$, except for $0,0.2$ and $0.4 \mathrm{mM}$. Also, statistical significance was found between the data for the high and low protease strains for all concentrations of $\mathrm{H}_{2} \mathrm{O}_{2}$, except for $0,0.2$ and $0.4 \mathrm{mM}$. Essentially identical results were obtained for strain W50 in both experiments. 
stresses of a fluctuating environment that include nutrient limitation and competition from other organisms in the associated biofilm. However, the most direct advantage of this particular bistable phenotype might be the ability to evade immune responses by accessing an immunologically privileged site (inside an epithelial cell). Indeed, earlier studies have identified several oral bacteria, including $P$. gingivalis, as members of an internalized flora within oral and buccal epithelial cells (Rudney et al., 2001, 2005). Other data from our laboratory also highlight that within the 'redcomplex' of periodontal pathogens this might be a unique phenotypic variation, since we were unable to enrich for invasive subpopulations of Tannerella forsythia in similar experiments (G. Stafford and W.-N. Wan Sulaiman, unpublished results). However, while the invasive nature of this bistability appears unique, other periodontal pathogens also display bistability, such as Campylobacter rectus, which displays reversible colony switching phenotypes (Gillespie \& Holt, 1987).

The bistable population of $P$. gingivalis was detected initially using an invasion enrichment method, and later by screening for low arginine-specific protease activity. Our data indicate that this phenotype might be due to reduced $\operatorname{rgpB}$ but not $\operatorname{rgpA}$ expression. Notably, no change in expression of the recently described Sov/PorT gingipain secretion system (Ishiguro et al., 2009; Sato et al., 2010) was observed in our microarray dataset. The importance of the gingipains has been well studied, and they have been shown to have a role in pigmentation, fimbriation and haemin utilization (Fitzpatrick et al., 2009). While their involvement in cell invasion is well established, the exact mechanism by which they influence cell uptake is less clearcut. Several groups have identified that their absence reduces invasion/adhesion efficiency (Lamont et al., 1992, 1995; Kadowaki et al., 1998), while others have indicated that it increases attachment to cells (Chen et al., 2001). Intriguingly, Arg-gingipain activity is thought to be of primary importance for $P$. gingivalis in the extracellular environment for both nutrient acquisition and defence against host responses (Genco et al., 1999). So although the cell-invasive, low protease phenotypes observed might possess improved intracellular survival characteristics they may be less able to respond to environmental challenges during extracellular life. However, in the event of a significant immune response, the invasive subtype would be able to escape into hiding and ensure the survival of the strain inside cells before later release back into the extracellular milieu, where its progeny would readjust the population to its baseline mixture of invasive and noninvasive subtypes. Such a concept could have implications for methods of periodontal treatment with therapeutic agents aimed at inhibiting Arg-gingipain. Strategies should perhaps be aimed at eradicating intracellular bacteria, not just those in the subgingival biofilm.

Our gene array datasets show a number of features in common with other studies that employed differential display and proteomics of related P. gingivalis strains (Park et al. 2004; Zhang et al., 2005) to examine responses to exposure to gingival epithelial cells. These notably included the stress response-associated genes $h s l R$ (heat shock protein 15, PG0165), trx (thioredoxin, PG1638) and $o x y R$ (oxygen-sensing transcription factor, PG0270), indicating that an increase in the expression of stress-response genes may be a widespread response of $P$. gingivalis to host cells. In addition, the invasion-related genes fimA (PG2132) and an internalin homologue (PG0350), and genes encoding 2amino-3-ketobutyrate CoA-ligase (PG0481 and PG1195), which are involved in threonine metabolism, were also coordinately regulated, indicating some shared responses between these studies.

When the transcriptomes of the low proteinase and high invasion phenotypes were compared for the two strains, a small set of common gene expression changes was seen (see Table 1). These appear then to represent a 'signature set' of genes that are associated with the phenotype of high invasion and survival within the assay system employed. Amongst the genes in the signature set were ones involved in iron utilization, maybe due to the low-iron environment within endocytic vesicles in which internalized bacteria find themselves, at least initially. Examples include $h m u R$ and $f e o B-1$ and -2. The hmuR (PG1552) gene encodes a TonBdependent outer membrane haemin utilization transporter, which is known to be regulated by iron levels and which possesses a Fur (ferric uptake regulator; PG0465) binding site in its promoter region (Simpson et al., 2000). The feoB-1 (PG1043) gene encodes an inner membrane ferrous iron uptake protein that is essential for pathogenesis of $P$. gingivalis and is also thought to be Fur-dependent (Dashper et al., 2005). The upregulation of these genes implies intracellular iron limitation, and indeed $h m u R$, PG1638 and $f e o B-2$ are among a set of $P$. gingivalis genes identified by others as regulated in response to haemin limitation (Dashper et al., 2009). Thus, our data would be in keeping with a concept of haemin or iron limitation in the intracellular environment and the adaptations made by our invasive subtypes would reflect this also.

Another prominent type of gene in our 'signature set' were those related to oxidative stress, such as the regulator $\operatorname{oxy} R$ and the gene encoding superoxide dismutase, $\operatorname{sod} B$. The OxyR (PG0270) protein is known to regulate several oxidative stress genes in P. gingivalis (Diaz \& Rogers, 2004; Diaz et al., 2006), and although they were not present in our signature set, a selection were regulated in the invasive/ non-invasive and protease strains, including $a h p C$ (alkylhydroperoxidase, PG0430) and uspA (oxidative stress resistance, PG0245), which are known to be key genes for stress resistance in $P$. gingivalis (Ueshima et al., 2003; Johnson et al., 2004; Chen et al., 2006). These data indicate that the invasive subtypes are likely to be well adapted to their intracellular environment, and indeed we found that they retained greater viability after exposure to hydrogen peroxide (Fig. 5). It is of note that several of these oxidative stress genes have also been found to be regulated in response to haemin limitation (Dashper et al., 2009). 
This might be explained by cross-talk in their regulatory pathways, as it has been established in several organisms that $\operatorname{sodB}$ is regulated by Fur (Thompson et al., 2002; Fee, 1991; Ernst et al., 2005) and oxyR (Diaz et al., 2006). These transcriptomic observations implicate the involvement of global transcriptional regulators in the control of this adaptation, which might indicate the existence of a stochastic fluctuation in gene expression levels that gives rise to these subtypes. This explanation has been suggested for several other systems, such as Bacillus subtilis biofilms, where the stochastic fluctuations in sporulation regulators give rise to alterations in exopolysaccharide production in a bistable portion of the biofilm population (Veening et al., 2008; Chai et al., 2008). This is reminiscent of the $P$. gingivalis situation, in that we suggest that the production of gingipains by some cells in the population provides protection for the whole population, while a small subpopulation underexpresses this protein, which enables it to 'hide' inside cells should conditions require such a response. Indeed, the efficiency of $P$. gingivalis invasion of epithelial cells is known to vary with the cell type and with the bacterial strain (Duncan et al., 1993; Dorn et al., 2000). However, the exact mechanism by which the low protease phenotype facilitates invasion is unclear. Also, it is rare for more than $10 \%$ of $P$. gingivalis cells to invade even when large numbers are present. Such variation and low efficiency could be due to several factors, including (1) the number (availability) and activation state of the integrin receptors on the cells, (2) the availability of the $\alpha_{5} \beta_{1}$ integrin-fibronectin complex, (3) the bacterial adhesin density and genotype, and (4) the physiological state of the bacteria. It is possible that only certain bacteria within a population are in a suitable state or phase to invade and survive within epithelial cells. The significance of this might be that at a clinical site, even though only a small proportion of the organisms would invade the pocket epithelium, ultimately the strain or species could persist at the site. The relative importance of each of the signature set of genes that is associated with the invasive phenotype has yet to be established but is the subject of ongoing study.

\section{ACKNOWLEDGEMENTS}

We would like to thank Professor Mike Curtis for supplying the protease mutant strains. This work was funded by a Royal Thai Government PhD studentship to S.S. and C. W. I. D. and by Royal Society (UK) and the University of Sheffield Medical School devolved funds to G.P.S.

\section{REFERENCES}

Boisvert, H. \& Duncan, M. J. (2008). Clathrin-dependent entry of a gingipain adhesin peptide and Porphyromonas gingivalis into host cells. Cell Microbiol 10, 2538-2552.

Chai, Y., Chu, F., Kolter, R. \& Losick, R. (2008). Bistability and biofilm formation in Bacillus subtilis. Mol Microbiol 67, 254-263.

Chen, T. \& Duncan, M. J. (2004). Gingipain adhesin domains mediate Porphyromonas gingivalis adherence to epithelial cells. Microb Pathog 36, 205-209.
Chen, T., Nakayama, K., Belliveau, L. \& Duncan, M. J. (2001). Porphyromonas gingivalis gingipains and adhesion to epithelial cells. Infect Immun 69, 3048-3056.

Chen, W., Honma, K., Sharma, A. \& Kuramitsu, H. K. (2006). A universal stress protein of Porphyromonas gingivalis is involved in stress responses and biofilm formation. FEMS Microbiol Lett 264, 1521.

Curtis, M. A., Aduse-Opoku, J. \& Rangarajan, M. (2001). Cysteine proteases of Porphyromonas gingivalis. Crit Rev Oral Biol Med 12, 192-216.

Darveau, R. P., Pham, T. T., Lemley, K., Reife, R. A., Bainbridge, B. W., Coats, S. R., Howald, W. N., Way, S. S. \& Hajjar, A. M. (2004). Porphyromonas gingivalis lipopolysaccharide contains multiple lipid A species that functionally interact with both Toll-like receptors 2 and 4 . Infect Immun 72, 5041-5051.

Dashper, S. G., Butler, C. A., Lissel, J. P., Paolini, R. A., Hoffmann, B., Veith, P. D., O'Brien-Simpson, N. M., Snelgrove, S. L., Tsiros, J. T. \& Reynolds, E. C. (2005). A novel Porphyromonas gingivalis FeoB plays a role in manganese accumulation. J Biol Chem 280, 28095-28102.

Dashper, S. G., Ang, C. S., Veith, P. D., Mitchell, H. L., Lo, A. W., Seers, C. A., Walsh, K. A., Slakeski, N., Chen, D. \& other authors (2009). Response of Porphyromonas gingivalis to heme limitation in continuous culture. J Bacteriol 191, 1044-1055.

Diaz, P. I. \& Rogers, A. H. (2004). The effect of oxygen on the growth and physiology of Porphyromonas gingivalis. Oral Microbiol Immunol 19, 88-94.

Diaz, P. I., Slakeski, N., Reynolds, E. C., Morona, R., Rogers, A. H. \& Kolenbrander, P. E. (2006). Role of $\operatorname{oxy} R$ in the oral anaerobe Porphyromonas gingivalis. J Bacteriol 188, 2454-2462.

Dorn, B. R., Burks, J. N., Seifert, K. N. \& Progulske-Fox, A. (2000). Invasion of endothelial and epithelial cells by strains of Porphyromonas gingivalis. FEMS Microbiol Lett 187, 139-144.

Duncan, M. J., Nakao, S., Skobe, Z. \& Xie, H. (1993). Interactions of Porphyromonas gingivalis with epithelial cells. Infect Immun 61, 22602265.

Eick, S., Reissmann, A., Rodel, J., Schmidt, K. H. \& Pfister, W. (2006). Porphyromonas gingivalis survives within $\mathrm{KB}$ cells and modulates inflammatory response. Oral Microbiol Immunol 21, 231-237.

Ernst, F. D., Homuth, G., Stoof, J., Mader, U., Waidner, B., Kuipers, E. J., Kist, M., Kusters, J. G., Bereswill, S. \& van Vliet, A. H. (2005). Ironresponsive regulation of the Helicobacter pylori iron-cofactored superoxide dismutase SodB is mediated by Fur. J Bacteriol 187, 3687-3692.

Fee, J. A. (1991). Regulation of sod genes in Escherichia coli: relevance to superoxide dismutase function. Mol Microbiol 5, 2599-2610.

Fitzpatrick, R. E., Wijeyewickrema, L. C. \& Pike, R. N. (2009). The gingipains: scissors and glue of the periodontal pathogen, Porphyromonas gingivalis. Future Microbiol 4, 471-487.

Genco, C. A., Potempa, J., Mikolajczyk-Pawlinska, J. \& Travis, J. (1999). Role of gingipains $\mathrm{R}$ in the pathogenesis of Porphyromonas gingivalis-mediated periodontal disease. Clin Infect Dis 28, 456-465.

Gillespie, J. \& Holt, S. C. (1987). Growth studies of Wolinella recta, a Gram-negative periodontopathogen. Oral Microbiol Immunol 2, 105111.

Hamada, N., Watanabe, K., Sasakawa, C., Yoshikawa, M., Yoshimura, F. \& Umemoto, T. (1994). Construction and characterization of a fimA mutant of Porphyromonas gingivalis. Infect Immun 62, 1696-1704.

Houalet-Jeanne, S., Pellen-Mussi, P., Tricot-Doleux, S., Apiou, J. \& Bonnaure-Mallet, M. (2001). Assessment of internalization and viability of Porphyromonas gingivalis in $\mathrm{KB}$ epithelial cells by confocal microscopy. Infect Immun 69, 7146-7151. 
Ishiguro, I., Saiki, K. \& Konishi, K. (2009). PG27 is a novel membrane protein essential for a Porphyromonas gingivalis protease secretion system. FEMS Microbiol Lett 292, 261-267.

Johnson, N. A., Liu, Y. \& Fletcher, H. M. (2004). Alkyl hydroperoxide peroxidase subunit $\mathrm{C}(a h p C)$ protects against organic peroxides but does not affect the virulence of Porphyromonas gingivalis W83. Oral Microbiol Immunol 19, 233-239.

Kadowaki, T., Nakayama, K., Yoshimura, F., Okamoto, K., Abe, N. \& Yamamoto, K. (1998). Arg-gingipain acts as a major processing enzyme for various cell surface proteins in Porphyromonas gingivalis. J Biol Chem 273, 29072-29076.

Kadowaki, T., Takii, R., Yamatake, K., Kawakubo, T., Tsukuba, T. \& Yamamoto, K. (2007). A role for gingipains in cellular responses and bacterial survival in Porphyromonas gingivalis-infected cells. Front Biosci 12, 4800-4809.

Lamont, R. J., Oda, D., Persson, R. E. \& Persson, G. R. (1992). Interaction of Porphyromonas gingivalis with gingival epithelial cells maintained in culture. Oral Microbiol Immunol 7, 364-367.

Lamont, R. J., Chan, A., Belton, C. M., Izutsu, K. T., Vasel, D. \& Weinberg, A. (1995). Porphyromonas gingivalis invasion of gingival epithelial cells. Infect Immun 63, 3878-3885.

Madianos, P. N., Papapanou, P. N., Nannmark, U., Dahlen, G. \& Sandros, J. (1996). Porphyromonas gingivalis FDC381 multiplies and persists within human oral epithelial cells in vitro. Infect Immun 64, 660-664.

Maeda, H., Reibel, J. \& Holmstrup, P. (1994). Keratin staining pattern in clinically normal and diseased oral mucosa of lichen planus patients. Scand J Dent Res 102, 210-215.

Nakayama, K., Kadowaki, T., Okamoto, K. \& Yamamoto, K. (1995). Construction and characterization of arginine-specific cysteine proteinase (Arg-gingipain)-deficient mutants of Porphyromonas gingivalis. Evidence for significant contribution of Arg-gingipain to virulence. J Biol Chem 270, 23619-23626.

Nakayama, K., Yoshimura, F., Kadowaki, T. \& Yamamoto, K. (1996a). Involvement of arginine-specific cysteine proteinase (Arggingipain) in fimbriation of Porphyromonas gingivalis. J Bacteriol 178, 2818-2824.

Nakayama, K., Yoshimura, F., Kadowaki, T. \& Yamamoto, K. (1996b). Involvement of arginine-specific cysteine proteinase (Arggingipain) in fimbriation of Porphyromonas gingivalis. J Bacteriol 178, 2818-2824.

Park, Y., Yilmaz, O., Jung, I. Y. \& Lamont, R. J. (2004). Identification of Porphyromonas gingivalis genes specifically expressed in human gingival epithelial cells by using differential display reverse transcription-PCR. Infect Immun 72, 3752-3758.

Pike, R. N., Potempa, J., McGraw, W., Coetzer, T. H. \& Travis, J. (1996). Characterization of the binding activities of proteinase-adhesin complexes from Porphyromonas gingivalis. J Bacteriol 178, 2876-2882.

Potempa, J., Pike, R. \& Travis, J. (1997). Titration and mapping of the active site of cysteine proteinases from Porphyromonas gingivalis (gingipains) using peptidyl chloromethanes. Biol Chem 378, 223-230.

Rangarajan, M., Hashim, A., Aduse-Opoku, J., Paramonov, N., Hounsell, E. F. \& Curtis, M. A. (2005). Expression of Arg-gingipain RgpB is required for correct glycosylation and stability of monomeric Arg-gingipain RgpA from Porphyromonas gingivalis W50. Infect Immun 73, 4864-4878.

Rauch, E. M. \& Bar-Yam, Y. (2004). Theory predicts the uneven distribution of genetic diversity within species. Nature 431, 449-452.
Rudney, J. D., Chen, R. \& Sedgewick, G. J. (2001). Intracellular Actinobacillus actinomycetemcomitans and Porphyromonas gingivalis in buccal epithelial cells collected from human subjects. Infect Immun 69, 2700-2707.

Rudney, J. D., Chen, R. \& Sedgewick, G. J. (2005). Actinobacillus actinomycetemcomitans, Porphyromonas gingivalis, and Tannerella forsythensis are components of a polymicrobial intracellular flora within human buccal cells. J Dent Res 84, 59-63.

Sato, K., Naito, M., Yukitake, H., Hirakawa, H., Shoji, M., McBride, M. J., Rhodes, R. G. \& Nakayama, K. (2010). A protein secretion system linked to bacteroidete gliding motility and pathogenesis. Proc Natl Acad Sci U S A 107, 276-281.

Simpson, W., Olczak, T. \& Genco, C. A. (2000). Characterization and expression of HmuR, a TonB-dependent hemoglobin receptor of Porphyromonas gingivalis. J Bacteriol 182, 5737-5748.

Smits, W. K., Kuipers, O. P. \& Veening, J. W. (2006). Phenotypic variation in bacteria: the role of feedback regulation. Nat Rev Microbiol 4, 259-271.

Socransky, S. S., Haffajee, A. D., Cugini, M. A., Smith, C. \& Kent, R. L., Jr (1998). Microbial complexes in subgingival plaque. J Clin Periodontol 25, 134-144.

Sojar, H. T., Hamada, N. \& Genco, R. J. (1997). Isolation and characterization of fimbriae from a sparsely fimbriated strain of Porphyromonas gingivalis. Appl Environ Microbiol 63, 2318-2323.

Thompson, D. K., Beliaev, A. S., Giometti, C. S., Tollaksen, S. L., Khare, T., Lies, D. P., Nealson, K. H., Lim, H., Yates, J., III \& other authors (2002). Transcriptional and proteomic analysis of a ferric uptake regulator (Fur) mutant of Shewanella oneidensis: possible involvement of Fur in energy metabolism, transcriptional regulation, and oxidative stress. Appl Environ Microbiol 68, 881-892.

Tsuda, K., Furuta, N., Inaba, H., Kawai, S., Hanada, K., Yoshimori, T. \& Amano, A. (2008). Functional analysis of $\alpha 5 \beta 1$ integrin and lipid rafts in invasion of epithelial cells by Porphyromonas gingivalis using fluorescent beads coated with bacterial membrane vesicles. Cell Struct Funct 33, 123-132.

Ueshima, J., Shoji, M., Ratnayake, D. B., Abe, K., Yoshida, S., Yamamoto, K. \& Nakayama, K. (2003). Purification, gene cloning, gene expression, and mutants of Dps from the obligate anaerobe Porphyromonas gingivalis. Infect Immun 71, 1170-1178.

Veening, J. W., Igoshin, O. A., Eijlander, R. T., Nijland, R., Hamoen, L. W. \& Kuipers, O. P. (2008). Transient heterogeneity in extracellular protease production by Bacillus subtilis. Mol Syst Biol 4, 184.

Yilmaz, O. (2008). The chronicles of Porphyromonas gingivalis: the microbium, the human oral epithelium and their interplay. Microbiology 154, 2897-2903.

Yilmaz, O., Watanabe, K. \& Lamont, R. J. (2002). Involvement of integrins in fimbriae-mediated binding and invasion by Porphyromonas gingivalis. Cell Microbiol 4, 305-314.

Yoshimura, F., Murakami, Y., Nishikawa, K., Hasegawa, Y. \& Kawaminami, S. (2009). Surface components of Porphyromonas gingivalis. J Periodontal Res 44, 1-12.

Zhang, Y., Wang, T., Chen, W., Yilmaz, O., Park, Y., Jung, I.-Y., Hackett, M. \& Lamont, R. J. (2005). Differential protein expression by Porphyromonas gingivalis in response to secreted epithelial cell components. Proteomics 5, 198-211.

Edited by: M. Kilian 